\title{
A CASE OF EXTREME EMPHYSEMA UNIVERSALLY AFFECTING BOTH LUNGS (HONEYCOMB LUNG) IN A CHILD OF FIVE YEARS. ${ }^{1}$
}

\author{
By Geo. S. Mrdoleton, M.A., M.D., Glasgow; and Alex. R. \\ Ferguson, M.D., Cairo.
}

\section{(Plates XXXVI. and XXXVII.)}

Cases of so-called honeycomb lung are of sufficient rarity to merit record. The following is the only one that has come under my observation in thirty year's' experience.

Among the cases already reported there has been considerable dissimilarity, and there has been diversity of opinion as to the pathological condition. Most have been described as cases of bronchiolectasis, some as emphysema, and others as vomicæ from the breaking-down of broncho-pneumonic consolidations. Probably the honeycomb lung can be produced in all these various ways.

CASE. - The patient, a girl æt. 5 years, was admitted in 1903 to the Royal Hospital for Sick Children on account of breathlessness and cough of six months' duration with steady loss of flesh. At birth she looked a healthy child, but at the age of 3 months she developed bronchitis, to which she had been subject every now and again since that time, though she never had a very bad cough and only very occasionally got a "a kind of blue." She began to walk at 11 months, and as she got older ran about, like other children, without breathlessness. She had had measles, whooping-cough, and chicken-pox, and was reported to have made a good recovery from them all. One brother suffered from tuberculous glands in the neck, and there was a history of tubercle in the father's family.

During the six months prior to admission she had gone off her food and had been inclined to sickness and romiting. Cough had been troublesome, especially at night, and for seven weeks before admission had been accompanied by a frothy spit tinged with blood, and it was observed that she got blue about the lips when coughing.

The child was emaciated, weighing only $24 \mathrm{lb}$., and there was marked lividity of the cheeks, lips, and finger-tips. There was a degree of orthopnoea, but the respirations, numbering from 30 to 40 , were easy. The chest presented something of the pigeon-breast shape, and during inspiration there was slight recession of the intercostal spaces. The percussion note over the lungs was generally resonant, but at the right apex, behind, less resonant than else-

${ }^{2}$ Communicated by Dr. Middleton to the Meeting of the Association of Physicians at Edinburgh in June 1908. [Received January 18, 1910.] 
where. The respiratory murmur was feeble, especially at the right apex. All over both lungs from apex to base small moist râles were audible. There was slight cough without expectoration. There was no enlargement of the cardiac dulness, and the sounds were pure but unduly well conducted to the right apex in front. There was a leucocytosis to the extent of 19,400 per cm., the leucocytosis being mostly of the polymorpho-nuclear variety. The abdominal organs were normal.

During her residence in hospital the physical signs remained practically as above noted, except that for a short time the râles became less abundant, thereafter becoming even more abundant than they were at first. She had

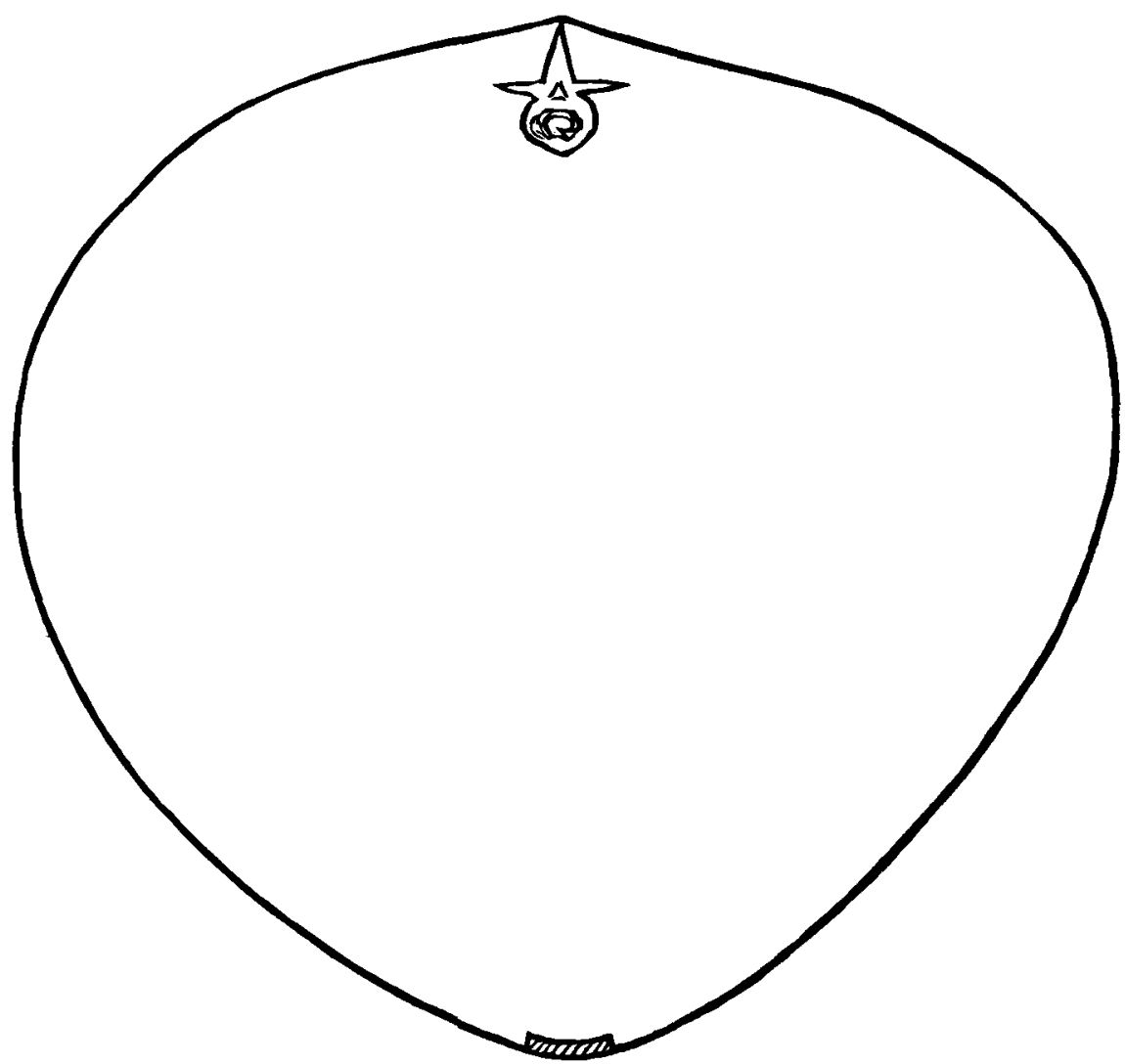

FIG. 1.-Cyrtometer tracing of chest one inch below nipple, taken March 9, 1903.

Right, $9 \frac{1}{2}$ inches ; left, $9 \frac{7}{7}$ inches (two.thirds natural size.)

very little cough and never any expectoration. The temperatures were practically non-pyrexial, but they presented oscillations between $97^{\circ}$ and $99^{\circ} .8 \mathrm{~F}$., the latter being recorded only on one occasion. In the last week of her life the respirations and the pulse became more rapid, the former running from 50 to 70 , and the latter ranging about 140 . Lividity increased and she gradually sank, dying seventeen days after admission.

The case was regarded as probably one of miliary tuberculosis of the lungs with catarrh, but the absence of fever rendered the diagnosis somewhat doubtful.

The pathological report by Dr. Ferguson which follows shows 
clearly that in this instance the cause of the honeycomb lungs was a universal bilateral emphysema.

The question arises, can such cases be diagnosed clinically? Attempts have been made by various writers to describe the physical signs likely to be met with, but $I$ am inclined to believe that until we know more of the mode of evolution of such cases we are not likely to recognise them with certainty during life.

Naked-eye Description of the Lungs.-The lungs were voluminous and distinctly bulged forwards in the chest-opening after removal of the sternum and costal cartilages; they encroached greatly also on the anterior surface of the heart, so that a very small portion of the anterior pericardium was exposed. There were no pleural adhesions on either side, and the pleural cavities were healthy.

The lungs generally were of salmon-flesh colour, and their pleural surfaces were dotted with innumerable small projecting bullæ varying in size from that of a small shot to that of a pea. These were of various tints, some being clear and vesicular, others darker. They were present in every part of both lungs, and gave to the organs in section a finely honeycombed appearance. It was noticed that the lungs "creaked" on section, but did not collapse on being laid open, as so regularly happens in emphysema of the adult.

The general characters of the lungs in cut section are shown in Plate XXXVI. Fig. 1.

Microscopical Description of the Condition.-Three sets of microscopical sections were prepared: (1) A series of large sections (measuring 6.5 by $5.5 \mathrm{cms}$.) were prepared by Mr. Richard Muir of the Edinburgh University Pathological Department. A low-power micro-photograph of one of these sections is shown in Plate XXXVII. Fig. 2. (2) A series of sections (2.5 by 3 cms.) were stained with various reagents, e.g. hæmalum and eosin, hæmatoxylin and Van Gieson's fluid, orcein and the Gram-Weigert method. (3) A series of small sections, cut as thinly as possible, for the more minute histological details.

Naled-eye examination of sections of series (1) and (2) shows the tissue riddled with circular, oval, or in a few cases, irregularly shaped but always rounded cavities. These have clearly defined walls. Small irregular patches of consolidation occur throughout, but these are neither extensive in area nor (to the naked eye) extreme in degree. The cavities are so numerous that only small patches in which the pulmonary reticulum has a normal appearance occur interspersed between them and the consolidated areas. The pleura is not thickened nor adherent in any way. The cavities exhibit every variation in size between diametric limits of 0.5 and $4 \mathrm{~mm}$.

Examination under moderate power (Zeiss, AA lens, compensating ocular No. 6) reveals, at once, the fact that the entire lung tissue, between the large cavities briefly described above, is affected with emphysema. The interalveolar septa are in many cases converted into extremely thin lamellæ, which in section at right angles to their plane appear as darkly staining lines destitute of any trace of capillaries or endothelial investment. Elsewhere, however, where the degree of septal atrophy is not so extreme, traces of the endothelial lining exist here and there. The endothelial cells are small, and, where several oceur in their normal juxtaposition, are seen to be of irregularly cubical form. The persisting capillaries in the thinned alveolar septa have exceedingly delicate walls and are of much smaller calibre than normal. Capillary thromboses were not found in any of these vessels. (See Plate XXXVII. Fig. 3. A small bronchus in the vicinity of the main cavity is scarcely dilated at all.) 
All the cavities, large and small, are devoid of contents. The largest cavities of all have sharply defined walls which are formed of very delicate lamellæ of somewhat cellular connective tissues in which very little trace of elastic fibres can be found in appropriately stained specimens. It may be noted here that the elastic tissue of the lung in general is much diminished. Only in very few instances is there microscopical evidence that the cavities may have had their origin in dilatation of bronchioles, which as a rule show no such change. In these cases (and they do not form the largest cavities) some portion of the cavity-it may be a very small arc of the circumference-is lined by cylindrical epithelium in all respects sirnilar to that found in the more typical bronchi met with in section elsewhere.

One is thus forced to the conclusion that the majority at any rate of the cavities in the lung have had a common origin, namely, in alveoli which have undergone either dilatation (in the case of the smaller cavities) or dilatation with rupture and subsequent atrophy of the interalveolar septa (in the case of the larger cavities).

The bronchi (see section of bronchus in Plate XXXVII. Fig. 4) are lined by a single layer of typical cylindrical epithelium, whose integrity is, in the case of most, not interfered with by any inflammatory process. Their muscular walls, in every instance, are atrophied, and they are deficient in elastic tissue. Their lumina are clear and show no granular or cellular contents. A few of the smaller bronchi, however, contain some granular material in which occur a few polymorpho-nuclear leucocytes. In other instances, however, the bronchi are evidently the centres of a limited area of alveolar consolidation. The air spaces, whose walls are thickened and infiltrated, are in these situations occupied by small cells, mainly mono1uclear, amongst which scanty alveolar epithelial cells, lightly charged with carbonaceous pigment, can be sometimes detected. The bronchial channels often assume irregular forms, as if their tubular character has been interfered with by the encroachments from without of some of the cavities.

With regard to the areas of consolidated appearance, these vary somewhat in nature. Their size (1 to $3 \mathrm{~mm}$.) confers a nodular appearance on the section, not unlike that of a lung affected with general tuberculosis; it may be said at once that there is no evidence of this disease in any part. ${ }^{1}$ (See Plate XXXVII. Fig. 2.)

In some of these areas the essential change consists in a fibrous thickening of the alveolar walls, with a dense infiltration of the interalveolar tissue with spindle-shaped connective tissue elements and leucocytes. The alveoli involved are much reduced in size, and occupied by desquamated endothelial cells of swollen spherical form, with some leucocytes. In parts the leucocytic content of the alveoli is predominant, and there is also in the interstitial tissue of these districts a rich leucocytic infiltration. Micro-organisms, however, are not demonstrable to any extent in these areas, and the change in all

${ }^{1}$ I (A. R. F.) have since had a case brought to my notice by Dr. Ivy M'Kenzie which to the naked eye closely resembled our present case. In Dr. M'Kenzie's case, however, the condition was one of acute general tuberculosis of the Iung in a child, accompanied by widespread enphysema, the cavities being in close relationship with the tubercle nodules, and often surromuling them. The change here was probably caused by the obstructive effect exercised on the bronchioles and alveoli by the tubercles, which were very numerous. 
probability is due to emigration from the congested vessels in the immediate neighbourhood. There is a rich capillary network in the densely cellular connective tissue of these foci of consolidation.

In other cases the cellular areas are due to purely interstitial infiltration with cells of mononuclear character-many of them of lymphocyte type. So much is this the case that it may reasonably be inferred that they are the results of obstruction of lymphatic. channels.

The condition of the larger vessels in the lung does not call for any detailed description. The lung tissue generally, as might be anticipated from its extremely emphysematous condition, shows a marked degree of anæmia, and the vessels, arteries as well as veins, are of relatively sinall size. The arterial walls are practically normal, and the elastic tissue of their intimal and adventitial coats forms, in the case of the medium-sized and smaller arteries, a striking feature in orcein-stained specimens. In and around the perivascular and peribronchial lympathic tracts is a certain amount of carbonaceous. pigment, but everywhere this occurs in small quantity. Here and there the small clumps of pigment are surrounded by collections of deeply stained lymphocytes.

The interpretation of all the phenomena described with regard to. their probable sequence in time is not easy. But it is very probable that the emphysema had been induced by a previous attack of bronchopneumonia, of which traces still exist in areas of persisting consolidation of the lung tissue and in the scattered foci of interstitial infiltration.

There are not many references in literature which agree in the more important features with the case just described.

A somewhat allied condition, described in Allbutt's "System of Medicine" (1903 $\left.{ }^{1}\right)$ under the title of "Capillary Bronchiectasis or Bronchiolectasis," is referred to past attacks of measles or whoopingcough as the exciting causes. In this article reference is made to. cases described by Sharkey $\left(1892^{2}\right)$. The second case described by this author agrees in certain clinical and pathological features with ours, though in his case bronchiolectasis was the outstanding feature, whereas in that we now describe the main lesion was alveolar emphysema. A case practically identical with ours is described by Morley Fletcher $\left(1901^{3}\right)$ in which the exciting cause was an attack of bronchitis at the age of 4 months, death occurring when the child had reached the age of $3 \frac{1}{2}$ years. The four cases described by Carr (1891 $)$, have no close relationship with our present case, differing from it in the following respects:- $(a)$ The nature of the lesion, which was distinctly bronchiectatic; (b) its partial distribution; and (c) the presence of dense pleural adhesions which appear to bring the cases. described by him more into line with similar changes occurring in adults under comparable conditions. 


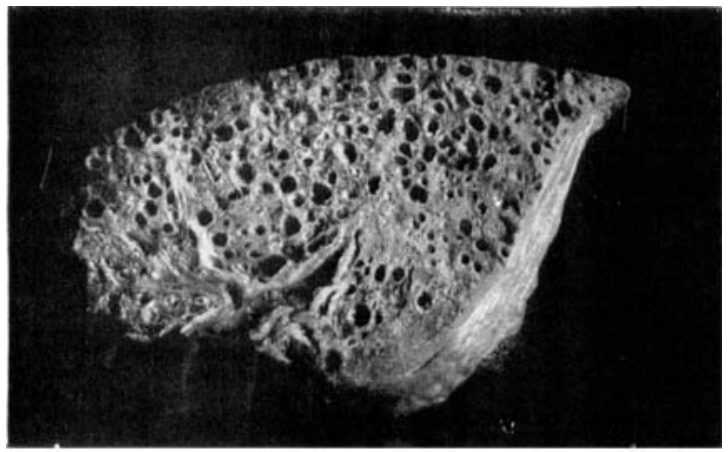

i is

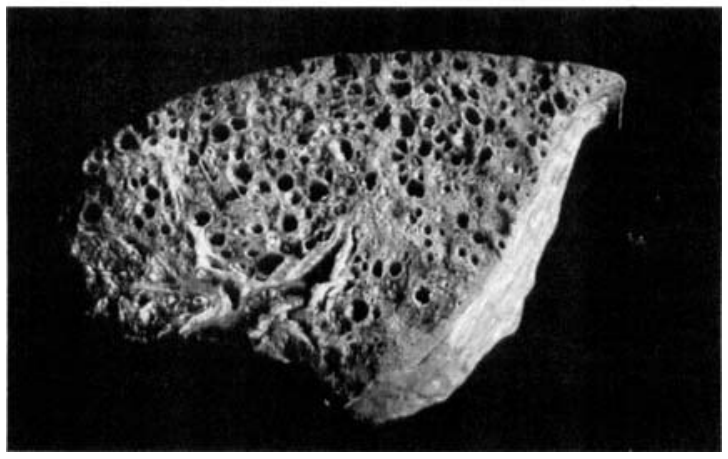




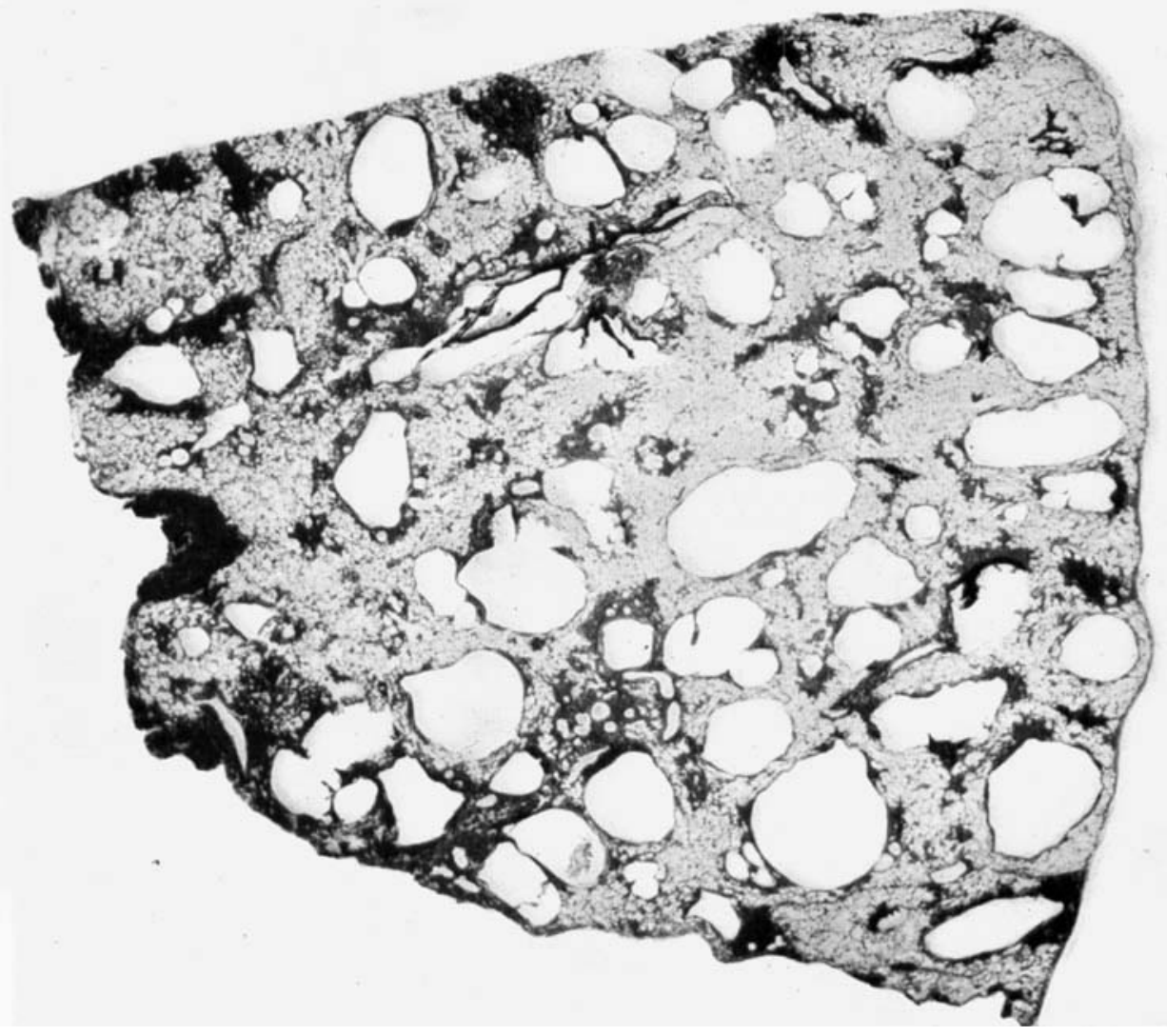

Fig. 2.

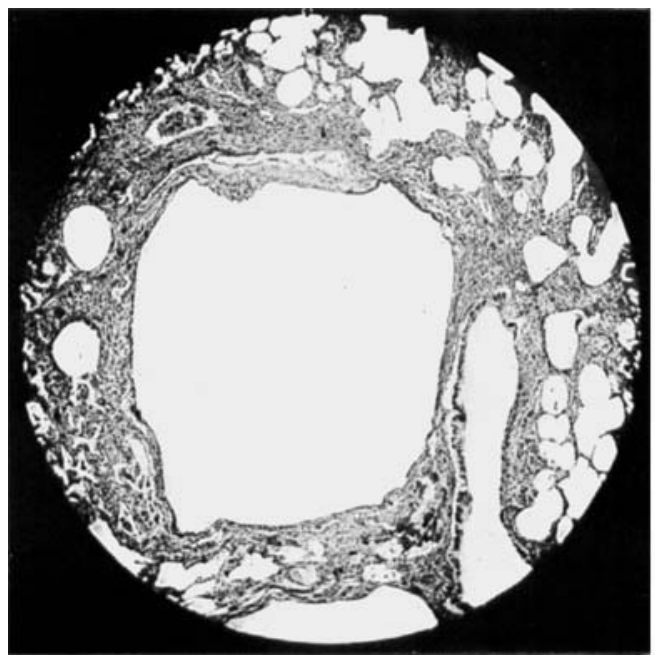

Fig. 3.

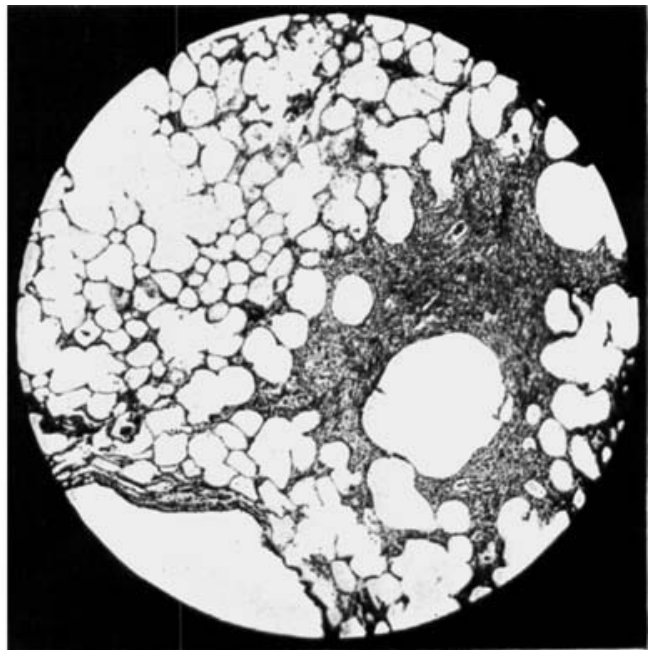

Fig. 4. 


\section{REFERENCES.}

1. Ewart . . . . . Allbutt's "System of Medicine," London, 1903, vol.v. p. 161.

2. Sharkey . . . . . . "Acute Bronchiectasis," St. Thomas Hosp. Rep., London, 1892, vol. xxii. p. 33.

3. Morley Fletcher . . "Pericholangitis with Cyst Formation, associated with Acute Bronchiolectasis," Trans. Path. Soc. London, 1901, vol. lii. p. 193.

4. CARr . . . . . . " "Bronchiectasis in Young Children," Practitioner, London, 1891, vol. xlvi. p. 87.

5. Fowler and Godlee . . "Diseases of the Lungs," London and N.Y., 1898 , chap. ix.

6. Howard Tootr . . . "Multiple Cavities in Broncho-pneumonia," Trans. Path. Soc. London, 1897, vol.

7. xlviii. p. 30 .

7. Box . . . . . . . "Bronchiectasis in Childhood," Trans. Med. Soc. London, vol. xxix. p. 151 . See also Lancet, London, 1907, vol. i. p. 16.

DESCRIPTION OF PLATES XXXVI. AND XXXVII.

\section{Plate XXXVI.}

Fig. 1. - Section of whole of left ling (for stereoseope).

\section{Plate XXXVII.}

FIG. 2.-Section magnified 4 diameters.

Fig. 3. - Section magnified 45 diameters.

FIa. 4. -Section magnified 45 diameters. 